\title{
Substantial asexual recruitment of mushroom corals contributes little to population genetics of adults in conditions of chronic sedimentation
}

\author{
James P. Gilmour* \\ Department of Zoology, University of Western Australia, 35 Stirling Hwy., Crawley 6009, Australia
}

\begin{abstract}
The contribution of asexual versus sexual recruitment to populations of the mushroom coral Fungia fungites was investigated at 2 sites with contrasting sediment regimes, located $5 \mathrm{~km}$ apart in the Dampier Archipelago (Western Australia). One site was exposed to high levels of chronic sedimentation, and many of its $F$. fungites polyps were asexual buds attached to dead parent polyps. A total of 95 buds were sampled from 26 parent skeletons; all buds on each parent were of the same genotype. The second site received less than half the sediment load, and the $F$. fungites polyps there were not observed to produce asexual buds. I hypothesised that asexual and sexual recruitment would contribute disproportionately to the maintenance of the high- and low-sediment sites respectively. However, electrophoretic analysis of 7 polymorphic loci indicated that sexual recruitment was responsible for the majority of adults in a random sample $(n=120)$ of polyps from each site. All polyps sampled at the low-sediment site had unique 7 locus genotypes. Between 10 and $30 \%$ of the polyps at the sediment-affected site were derived asexually, but all were in juvenile size classes, usually as replicate buds attached to a single parent. No adult polyps shared the same genotype, despite evidence that rarely, some asexual recruits may survive to adult size. Patterns of sexual recruitment underlying both populations were characterised by major heterozygote deficiencies and considerable inbreeding $\left(F_{\mathrm{IS}}=0.571 \pm 0.018 \mathrm{SE}\right)$. Most genetic differentiation occurred between locations within sites $\left(F_{\mathrm{ST}}=0.080\right)$ rather that among sites $\left(F_{\mathrm{ST}}=0.022\right)$. Dispersal of gametes and larvae appear to be highly localised.
\end{abstract}

KEY WORDS: Corals $\cdot$ Fungiid $\cdot$ Fungia fungites $\cdot$ Sex $\cdot$ Asexual reproduction $\cdot$ Electrophoresis $\cdot$ Coral recruitment $\cdot$ Dampier $\cdot$ Archipelago

Resale or republication not permitted without written consent of the publisher

\section{INTRODUCTION}

The life histories of many clonal marine organisms include episodes of sexual and asexual reproduction (Jackson \& Coates 1986, Hughes 1989, Avise 1994). The selective advantages of sexual versus asexual reproduction change under different conditions, and energy allocation into each reproductive mode may reflect changes in the environment (Bradshaw 1965, Jackson \& Coates 1986, Stearns 1992). Reproductive plasticity, and its affect on population structure, are often generalised in life-history theory. Traditional

*E-mail: jgilmour@cyllene.uwa.edu.au models predict that when local conditions are favourable and levels of disturbance to a population are low, then energy allocation into asexual growth and reproduction will predominate (Williams \& Mitton 1973, Warner 1975, Williams 1975). Such a population will be dominated by a few well-adapted genets. Conversely, when local conditions are unfavourable and levels of disturbance are high, individuals will theoretically invest more energy into sexual reproduction and dispersal (Warner 1975, Williams 1975, Carvalho 1994). In this case genet number will be high, due to removal of colonies by disturbance and the survival of sexual recruits in an unstable habitat (Bell 1982, Sebens \& Thorn 1985, Carvalho 1994). 
A primary assumption underlying these models is that asexual reproduction is positively correlated with the growth of an individual, and/or genet. Examples in clonal marine organisms include longitudinal fission, pedal laceration, and asexual planulation. Alternately, the life histories of some clonal marine organisms do not meet these assumptions. For example, asexual propagules may be generated by disturbance events, rather than stable conditions, and the size of the genet may decrease as a consequence. Fragmentation of coral colonies during storms is an example. In these cases, disturbance events are likely to decrease sexual output because of energy investment into tissue repair and the decrease in tissue area. Also, the local spread of asexual propagules may exclude sexual recruits, or dilute their representation within the population, thus reducing genotypic diversity.

Generalisations about the output of sexual versus asexual propagules in response to disturbance events, and their effect on local population structure, are not broadly applicable. For most clonal marine organisms, patterns of reproductive plasticity will be specific to the types of disturbance they are exposed to and the modes of sexual and asexual reproduction they utilise (e.g. Heyward \& Collins 1985, Hunter 1993, Coffroth \& Lasker 1998). Manipulative experiments may be used to quantify the reproductive plasticity of clonal marine organisms in response to disturbance treatments. However, quantifying proportional changes in the output of sexual or asexual propagules may not indicate their overall contribution to population structure. The wide dispersal distances of sexual larvae may result in little correlation between local levels of production and recruitment. Also, post-recruitment processes may affect sexual and asexual propagules differently, further decoupling any relationship between propagule output and adult population structure. The cumulative contribution of sexual and asexual recruitment to a population of clonal marine organisms can be investigated using genetic analysis. If asexual reproduction underlies population demography then it is reflected in the local proliferation of clone mates, and consequently, genet number will be low (e.g. Stoddart 1984, Russo et al. 1994, Coffroth \& Lasker 1998). If sexual recruitment underlies population demography, then neighbours will be unique genotypes, and genet number will approach the sample size for the population (e.g. Russo et al. 1994, Ayre et al. 1997, Coffroth \& Lasker 1998). The relative mortality rates of sexual and asexual propagules, and their importance to population maintenance, can be inferred from genetic data by comparing their proportional contribution to population size classes or life-history stages. Additionally, more detailed information about patterns of sexual reproduction, such as measures of inbreeding and scales of larval dispersal, may also be obtained.
In this study, the contribution of sexual versus asexual recruitment to the population genetics of the mushroom coral Fungia fungites (Lamark 1801) was investigated at 2 sites exposed to different sediment regimes. One site is exposed to high levels of sedimentation. Much of the reef matrix at this site is composed of dead polyps spanning a range of size classes, and dead parent polyps with asexual buds, indicating a long history of polyp mortality and bud production. Asexual bud production in F. fungites occurs following the apparent mortality of the parent polyp. This could be seen at the high-sediment site with a large proportion of asexual buds attached to the skeletons of parent polyps. Sedimentation has been found to cause size specific injury, mortality, and bud production in F. fungites at this study site (Gilmour 2002). The second site is exposed to less than half the levels of sedimentation of the first site, and no asexual bud production has been observed here. All polyps within the low-sediment site are either free-living or sexual recruits attached to the substrata. I predicted that within the sediment-affected site, the numerous asexual buds would contribute substantially to population maintenance. A low genet number and the presence of numerous clone mates in all sample size classes would reflect this contribution. Alternately, sexual recruitment was predicted to structure the population exposed to low sedimentation, resulting in a genet number similar to the population sample. The first aim of this experiment was to confirm that polyps attached to skeletons of $F$. fungites were asexual buds produced by the parent, and to quantify the proportion that may have recruited to the parent skeleton sexually. The second aim was to determine the contribution of sexual and asexual recruitment to different polyp life-history stages in the 2 contrasting populations, and to infer the importance of each reproductive mode to population maintenance. Finally, patterns of sexual reproduction and recruitment in both populations were interpreted from genetic data.

\section{MATERIALS AND METHODS}

Study sites, species and sampling design. Study sites are located approximately $5 \mathrm{~km}$ apart in the Dampier Archipelago on the north-west coast of Western Australia. The low-sediment site is located on the leeward side of East Lewis Island, which lies north-west of the high-sediment Hamersley rocks site on the mainland (Fig. 1). The coral communities at both sites are small (1.5 to $2 \mathrm{~km}$ in length), shallow $(<10 \mathrm{~m})$ patch reefs that are isolated from other reefs within the Archipelago. Fungia fungites was common at both sites, although the abundance of its life-history stages were very dif- 


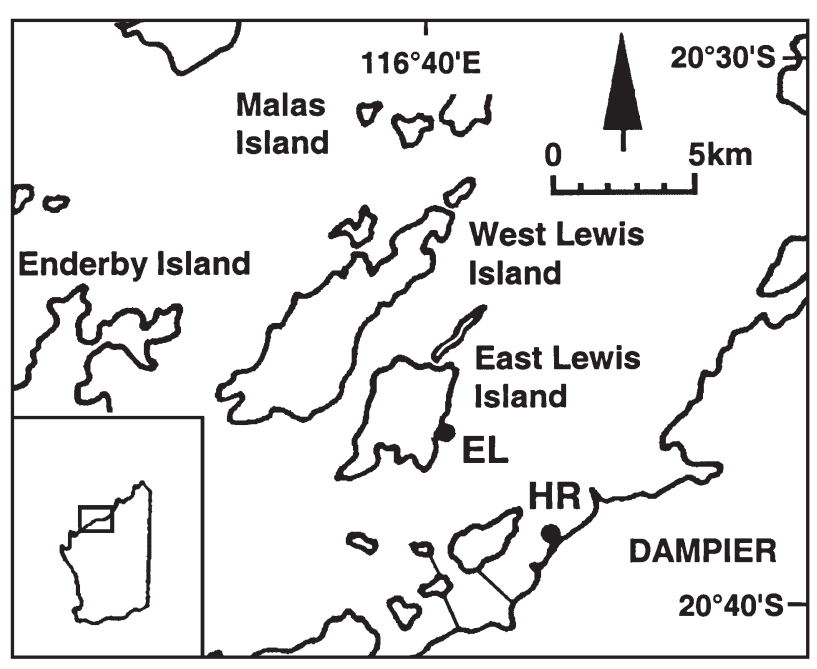

Fig. 1. Location $(\bullet)$ of the high- (HR) and low- (EL) sediment sites within the Dampier Archipelago, Western Australia

ferent. Asexual buds were only found at the high-sediment reef where they were the most abundant lifehistory stage, whereas sexual recruits were most abundant at the low-sediment reef. The most obvious physical difference between the reefs was their level of sedimentation. A comparative measure of sediment deposition was obtained by deploying 8 sediment traps (height $30 \mathrm{~cm} \times 5 \mathrm{~cm}$ diameter) at each reef, for a total of $87 \mathrm{~d}$. Sediment traps were deployed for a period of 7 to 14 d, every 4 to 6 mo, between September 1997 and March 2000. At each collection, the sediment samples were washed through $2 \mathrm{~mm}$ sieves, excess water was decanted and the sediment dried at $120^{\circ} \mathrm{C}$ for $3 \mathrm{~d}$ before weighing. Sedimentation at both reefs was greater during the summer months, when storm and cyclone disturbances are common, but varied between the reefs relative to prevailing wind and wave conditions. However, for 76 of the $87 \mathrm{~d}$ that sediment traps were deployed, the daily sediment load was 2 to 5 times greater at the high-sediment reef. Overall, the mean sediment load at the high-sediment reef (301 $\mathrm{g} \mathrm{m}^{-2} \mathrm{~d}^{-1} \pm 199 \mathrm{SD}$ ) was more than twice that at the low-sediment reef $\left(121 \mathrm{~g} \mathrm{~m}^{-2} \mathrm{~d}^{-1} \pm 86 \mathrm{SD}\right)$.

Fungia fungites is a solitary mushroom coral that reproduces sexually and asexually. The species is dioecious and broadcasts its gametes during the mass coral spawning that occurs in March/April of each year in Western Australia. Sexual larvae settle and remain attached to the substrata by a stalk, until they grow to a size of detachment and become free-living polyps. Asexual budding in F. fungites is a consequence of polyp injury. Adult tissue in the region of injury regresses into the spaces between the septae and costae of the skeleton, and emerges months later as visible buds (see Boschma 1923, Krupp et al. 1992, Kramarsky-Winter \& Loya 1996). Sediment accumulation on the surface of $F$. fungites polyps causes injury, resulting in parent mortality and the emergence of buds approximately 6 mo after sediment addition (Gilmour 2002). Asexual buds also detach to become free-living polyps, but the size at which they detach is generally smaller $(\approx 2.5 \mathrm{~cm}$ diameter) than for sexual recruits $(\approx 6.5 \mathrm{~cm}$ diameter). There are 5 general lifehistory stages of $F$. fungites discussed in this study; sexual recruits that are attached to the substrata; asexual buds that are attached to polyp skeletons; parent polyp skeletons on which asexual buds are attached; free-living juvenile polyps that are sexually or asexually derived; and free-living adult polyps that are sexually mature ( $\geq 9 \mathrm{~cm}$ diameter). The size of polyp maturity is based on the presence of eggs in polyps ( $\mathrm{n}=36$ ) of between 5 and $21 \mathrm{~cm}$ diameter, sampled prior to spawning in 1998 and 1999.

At each site, 4 locations separated by $100 \mathrm{~m}$ were sampled along a transect parallel to the shore. At each location, 30 of the closest polyps to co-ordinates generated from random number tables were collected from within a $1 \mathrm{~m}^{2}$ area. A total of 120 specimens were collected from each of the 2 study sites. Specimens were classified into one of 3 life-history stages: free-living polyps, buds on parent polyps, or sexual recruits. Descriptive information such as fusion between polyps, partial polyp mortality and polyp size (cm diameter) were also recorded. An additional 60 buds were collected to confirm that they were asexually derived, and not wholly or partly due to the settlement of sexual larvae onto polyp skeletons. Within each of the 4 locations at the high-sediment site, 3 buds were collected from 5 different parent polyps. All specimens were stored in liquid nitrogen before extraction and analysis.

Electrophoresis. Samples of tissue and skeleton were crushed, and enzyme extraction followed the methods used by Johnson \& Threlfall (1987). Electrophoresis was carried out in horizontal starch gels using a tris-citrate (TC8), tris-EDTA-borate (TEB) or tris-malate (TM) buffer (buffers 5, 6 and 9 respectively of Selander et al. 1971). Enzymes investigated were glutamate dehydrogenase (EC 1.4.1.2; Gdh* locus; TC8 buffer); isocitrate dehydrogenase (EC 1.1.1.42; Idh* locus; TM buffer); malate dehydrogenase (EC 1.1.1.40; Mdhp* locus; TM buffer); phosphogluconate dehydrogenase (EC 1.1.1.44; Pdgh* locus; TC8 buffer); phosphoglucose isomerase (EC 5.3.1.9; Pgi ${ }^{*}$ locus; TEB buffer); phosphoglucomutase (EC 2.7.5.1; Pgm* locus; TM buffer) and peptidase valyl-leucine (EC 3.4.-.-; $V l^{*}$ locus; TEB buffer). Staining recipes were essentially those of Richardson et al. (1986), with the exception that concentrations of the substrate, co-factor, 
linking enzymes and dye were increased up to 4 times when enzyme activity was low. Alleles at each locus were labelled alphabetically in order of decreasing mobility of allozymes. Variation was assumed to be allelic and the observed isozyme patterns corresponded to those described for other species with normal Mendelian inheritance.

The maximum and minimum contribution of sexual and asexual reproduction to a population can be estimated by employing the following 2 models and assumptions. Firstly, the number of genets is assumed to equal the genetic contribution of sexual reproduction to a population $\left(\mathrm{N}_{\mathrm{g}}\right)$. The number of times a genet is recorded locally among physically separate individuals (ramets) is a measure of its asexual replication. Because few loci are analysed relative to the entire genome, genets may occur repeatedly by chance despite being a product of sexual recombination (Johnson \& Threlfall 1987). Consequently, the ratio of $\mathrm{N}_{\mathrm{g}}: \mathrm{N}$ (population number) provides a minimal estimate of sexual recruitment (number of genets) to a population. The remaining proportion therefore provides a maximal estimate of the contribution of asexual reproduction. Secondly, the expected proportion of repeated genets that are produced sexually, assuming panmixia, is a product of the probabilities of component singlelocus genotypes calculated from allelic frequencies. For a single genotype, the expected number of repeated genets that are sexually derived is $(N-1) g_{i}$, where $N-1$ is the sample size minus the first individual, and $g_{i}$ is the frequency of the genotype in the sample of sexual recruits. The upper $95 \%$ confidence limit (Table 41 in Pearson \& Hartley 1956) of this estimate is used to correct for sampling variance, to produce a maximal estimate of the sexual contribution to a population $\left(\mathrm{N}^{*}\right)$ (Johnson \& Threlfall 1987). $\mathrm{N}^{*}$ was calculated only for the high-sediment site, from allele frequencies for the total population sample. The ratio $\mathrm{N}^{*}: \mathrm{N}$ estimates the maximum proportion of the population generated sexually while the remaining proportion is therefore a minimal estimate of the contribution of asexual reproduction.

Three different measures of sexual and asexual recruitment were obtained depending on the lifehistory stages of polyps that were included in the data. The first measure included all polyps sampled randomly at each population. The second measure quantified the dispersal of genets throughout the population and therefore excluded more than 1 asexual bud from a single parent polyp or more than 1 specimen taken from fused polyps. The final measure quantified the contribution of asexual reproduction to the adult population and therefore only included repeats of genets that were spatially dispersed and above the size of sexual maturity ( $\geq 9 \mathrm{~cm}$ diameter).
Analysis: Patterns of sexual recruitment. The supply of sexually produced larvae to the low- and highsediment sites was investigated by comparing the genotypic frequencies of genets with those expected under Hardy-Weinberg equilibrium. Each genet was included only once at each population. Expected genotypic frequencies were calculated using BIOSYS-1 (Swofford \& Selander 1981) and compared with observed frequencies. The occurrence of rare genotypes required the pooling of heterozygotes and the pooling of homozygotes for each analysis. $\chi^{2}$ tests were used to determine if departures from Hardy-Weinberg equilibrium were significant, and the sequential Bonferroni technique used to correct for multiple comparisons (Rice 1989). Yates correction was applied when the smallest expected values were less than $10(\mathrm{~N}>40)$. Excesses (positive) or deficits (negative) of heterozygotes were expressed as the proportional deviation from expected heterozygosity $\left(D_{\mathrm{s}}\right)$ (Selander 1970).

Levels of genetic differentiation between and within sites of Fungia fungites were investigated using $F$ statistics. The standard genetic variation among sites $\left(F_{\mathrm{ST}}\right)$ and the standard genetic variation within sites $\left(F_{\text {IS }}\right)$ were calculated following the method of Weir \& Cockerham (1984). Each genet was included only once. $\chi^{2}$ tests were used to test the hypothesis of no genetic subdivision among sites (i.e. $F_{\mathrm{ST}}=0$ ) or within sites $\left(F_{\mathrm{IS}}=0\right)$. The following formulae were used; $\chi^{2}=$ $2 \mathrm{~N} F_{\text {ST }}(k-1)$ with $(k-1) \times(s-1)$ degrees of freedom $(\mathrm{N}=$ total number of specimens, $k=$ number of alleles at a given locus, $s=$ number of populations), and $\chi^{2}=$ $2 \mathrm{~N}\left(F_{\mathrm{IS}}\right)^{2}(k-1)$ with $k(k-1) / 2$ degrees of freedom. Average values were calculated by jack-knifing across loci (Reynolds et al. 1983). Hierarchical analysis of $F_{\mathrm{ST}}$ (Wright 1978) was used to partition genetic variation within and among sites.

\section{RESULTS}

\section{Asexual bud production in Fungia fungites and polyp fusion}

Multilocus genotypes for 95 polyps, attached to 29 parents, were inspected to confirm that they were derived asexually. All polyps sampled from a single parent had identical multilocus genotypes. In 3 instances, samples were collected from parent polyps with some live tissue and in all of these cases the buds and parent polyps had identical multilocus genotypes. There was no evidence of sexual recruitment to parent skeletons.

Polyp fusion was recorded only in the high-sediment site, between free-living adults or between buds attached to the parent skeleton. Additionally, fused 
polyps were approximately the same size regardless of whether they were buds or free-living polyps, indicating they were from the same cohort. Fusion was not observed between sexual recruits attached to the substrata despite their highly aggregated settlement patterns. Polyps attached to the substrata and abutting each other altered their growth and morphology, either growing over, under, or away from the adjacent polyp. In the genetic analysis of the high-sediment site, tissue was taken from a total of 15 polyps fused to at least 1 other polyp. Analysis of 6 pairs $(\mathrm{n}=12)$ and one group of $3(n=3)$ showed that all fused polyps had the same genotype. Observations of polyp fusion between asex-

Table 1. Fungia fungites. Allelic frequencies at 7 variable loci at 4 locations in 2 sites

\begin{tabular}{|c|c|c|c|c|c|c|c|c|}
\hline \multirow[b]{2}{*}{ Location } & \multicolumn{4}{|c|}{ Low-sediment site } & \multicolumn{4}{|c|}{ High-sediment site } \\
\hline & 1 & 2 & 3 & 4 & 1 & 2 & 3 & 4 \\
\hline & 30 & 30 & 30 & 30 & 30 & 30 & 30 & 30 \\
\hline \multicolumn{9}{|l|}{ Loci } \\
\hline \multicolumn{9}{|l|}{$\operatorname{Pgm}^{*}$} \\
\hline $\mathrm{A}$ & 0.017 & - & 0.017 & - & 0.033 & 0.033 & - & - \\
\hline B & 0.167 & 0.350 & 0.517 & 0.633 & 0.033 & 0.167 & 0.350 & 0.300 \\
\hline C & 0.500 & 0.417 & 0.333 & 0.300 & 0.100 & 0.583 & 0.367 & 0.600 \\
\hline $\mathrm{D}$ & 0.283 & 0.200 & 0.083 & 0.033 & 0.833 & 0.217 & 0.250 & 0.100 \\
\hline $\mathrm{E}$ & 0.033 & 0.033 & 0.050 & 0.033 & - & - & 0.033 & - \\
\hline \multicolumn{9}{|l|}{$M d h p^{*}$} \\
\hline A & - & - & - & - & - & 0.017 & - & 0.017 \\
\hline $\mathrm{B}$ & 0.483 & 0.417 & 0.283 & 0.450 & 0.500 & 0.550 & 0.367 & 0.450 \\
\hline $\mathrm{C}$ & 0.517 & 0.550 & 0.583 & 0.550 & 0.500 & 0.433 & 0.633 & 0.533 \\
\hline $\mathrm{D}$ & - & 0.033 & 0.133 & - & - & - & - & - \\
\hline \multicolumn{9}{|l|}{$I d h^{*}$} \\
\hline A & - & - & 0.117 & - & - & - & - & 0.033 \\
\hline B & 0.300 & 0.433 & 0.500 & 0.333 & 0.067 & 0.517 & 0.400 & 0.367 \\
\hline $\mathrm{C}$ & 0.500 & 0.400 & 0.333 & 0.650 & 0.833 & 0.217 & 0.100 & 0.367 \\
\hline $\mathrm{D}$ & 0.200 & 0.167 & 0.050 & 0.017 & 0.100 & 0.267 & 0.500 & 0.233 \\
\hline \multicolumn{9}{|l|}{ Pqi ${ }^{*}$} \\
\hline A & - & - & - & - & - & - & - & - \\
\hline B & 0.283 & 0.117 & 0.067 & 0.083 & - & 0.017 & - & 0.017 \\
\hline $\mathrm{C}$ & 0.267 & 0.283 & 0.517 & 0.267 & 0.150 & 0.167 & 0.283 & 0.350 \\
\hline D & 0.450 & 0.600 & 0.383 & 0.633 & 0.817 & 0.783 & 0.717 & 0.600 \\
\hline $\mathrm{E}$ & - & - & 0.033 & 0.017 & 0.033 & 0.033 & - & 0.033 \\
\hline \multicolumn{9}{|l|}{$V l^{*}$} \\
\hline A & - & - & - & - & - & 0.017 & - & - \\
\hline B & 0.200 & 0.150 & 0.117 & 0.167 & 0.917 & 0.233 & 0.467 & 0.283 \\
\hline $\mathrm{C}$ & 0.383 & 0.567 & 0.317 & 0.333 & 0.067 & 0.467 & 0.433 & 0.583 \\
\hline D & 0.383 & 0.283 & 0.567 & 0.500 & 0.017 & 0.283 & 0.100 & 0.133 \\
\hline $\mathrm{E}$ & 0.033 & - & - & - & - & - & - & - \\
\hline \multicolumn{9}{|l|}{$P d g h^{*}$} \\
\hline A & 0.017 & 0.133 & 0.050 & 0.133 & - & 0.133 & 0.067 & - \\
\hline B & 0.850 & 0.867 & 0.700 & 0.767 & 0.967 & 0.833 & 0.833 & 0.833 \\
\hline $\mathrm{C}$ & 0.133 & - & 0.217 & 0.100 & 0.033 & 0.033 & 0.100 & 0.133 \\
\hline $\mathrm{D}$ & - & - & 0.033 & - & - & - & - & 0.033 \\
\hline \multicolumn{9}{|l|}{$G d h^{*}$} \\
\hline A & 0.033 & 0.083 & 0.017 & 0.033 & - & 0.167 & - & 0.033 \\
\hline B & 0.283 & 0.167 & 0.133 & 0.267 & 0.733 & 0.483 & 0.600 & 0.550 \\
\hline C & 0.500 & 0.500 & 0.483 & 0.400 & 0.233 & 0.300 & 0.033 & 0.233 \\
\hline D & 0.183 & 0.183 & 0.333 & 0.283 & 0.033 & 0.050 & 0.367 & 0.183 \\
\hline $\mathrm{E}$ & - & 0.067 & 0.033 & 0.017 & - & - & - & - \\
\hline
\end{tabular}

ual buds but not between sexual recruits, coupled with these genetic data, suggest that fusion only occurs between clone mates produced through asexual budding.

\section{Allelic variation}

High levels of allozyme variation were detected within each of the 2 study sites (Table 1). Much of the allelic variation was common to both sites, although the range in the mean number of alleles per locus at each location was slightly higher at the low-sediment site (3.4 to 4.0$)$ than at the high-sediment site (2.9 to 3.4). The mean heterozygosity at each location was also slightly larger at the low-sediment site, ranging from 0.533 to 0.587 . A similar range $(0.510$ to 0.538 ) in mean heterozygosity was obtained for all but Location 1 at the high-sediment site, where the repeated sampling of asexual buds on parent polyps resulted in a comparatively low measure (0.214).

\section{The contribution of sexual and asexual recruitment to population structure}

Sexual recruitment underlies the population at East Lewis, which is exposed to low levels of sedimentation. All of the 120 specimens collected had unique 7-locus genotypes. No asexual buds and few dead polyps were observed inside or outside the sampling area. In contrast, much of the Hamersley Rocks site exposed to high-sediment levels contained dead polyps spanning the full range of size classes at various stages overgrowth by encrusting organisms. Fungiid skeletons were an important component of the reef matrix at the high-sediment site. Of 120 randomly sampled specimens, 52 were asexual buds attached to 20 parent polyps. Despite the frequency of asexual budding, the total number of genets identified at the high-sediment site was relatively large (78; Table 2).

Three different estimates of sexual and asexual recruitment to the highsediment site were obtained, depending on the life-history stages of speci- 
Table 2. Fungia fungites. Genet number and the estimated contribution of sexual and asexual recruitment to the high-sediment population. All polyps at the low-sediment population were sexually derived. 'All specimens' include all polyps in the sample; 'physically separate polyps' exclude more than 1 bud on a single parent and more than 1 polyp in a fused set; and 'separate mature polyps' are all above the reproductive size $(9 \mathrm{~cm}$ diameter), excluding more than 1 polyp in a fused set. N: total number of polyps; Ng: number of genets (minimum sexual contribution); $\mathrm{Ng}: \mathrm{N}$ : minimum proportion of sexual recruits; $\mathrm{N}^{*}$ : maximum proportion of sexual recruits calculated from allele frequencies of the total population sample; $N^{*}: N$ : maximum proportion of sexual recruits to the population

\begin{tabular}{|c|c|c|c|c|c|c|c|c|c|c|c|c|c|c|c|c|c|}
\hline \multirow[t]{2}{*}{ Location } & \multicolumn{3}{|c|}{1} & \multicolumn{3}{|c|}{2} & \multicolumn{3}{|c|}{3} & \multicolumn{3}{|c|}{4} & \multicolumn{5}{|c|}{ All locations } \\
\hline & $\mathrm{N}$ & $\mathrm{Ng}$ & $\mathrm{Ng}: \mathrm{N}$ & $\mathrm{N}$ & $\mathrm{Ng}$ & $\mathrm{Ng}: \mathrm{N}$ & $\mathrm{N}$ & $\mathrm{Ng}$ & $\mathrm{Ng}: \mathrm{N}$ & $\mathrm{N}$ & $\mathrm{Ng}$ & $\mathrm{Ng}: \mathrm{N}$ & $\mathrm{N}$ & $\mathrm{Ng}$ & $\mathrm{Ng}: \mathrm{N}$ & $\mathrm{N}^{*}$ & $\mathrm{~N}^{*}: \mathrm{N}$ \\
\hline All specimens & 30 & 12 & 0.40 & 30 & 24 & 0.80 & 30 & 21 & 0.70 & 30 & 21 & 0.70 & 120 & 78 & 0.65 & 82 & 0.68 \\
\hline $\begin{array}{l}\text { Physically separate } \\
\text { polyps }\end{array}$ & 17 & 12 & 0.71 & 24 & 23 & 0.96 & 21 & 19 & 0.90 & 22 & 21 & 0.95 & 84 & 75 & 0.89 & 77 & 0.92 \\
\hline $\begin{array}{l}\text { Separate mature } \\
\text { polyps }\end{array}$ & 5 & 5 & 1.00 & 10 & 10 & 1.00 & 9 & 9 & 1.00 & 7 & 7 & 1.00 & 33 & 33 & 1.00 & - & - \\
\hline
\end{tabular}

mens included in the data. When including all specimens, the minimum and maximum contribution of sexual reproduction was 65 and $68 \%$ respectively, and therefore the minimum and maximum estimate of asexual reproduction was 32 and $35 \%$ respectively (Table 2). Within this sample are 22 cases of genet repeats, of which 16 are due to the analysis of fused polyps or more than 1 bud from a single parent polyp. There was a similar number of genets in each of the random samples from the different locations, and therefore the relative contribution of sexual and asexual reproduction (Table 2). The exception was Location 1 , in which fewer genets were present because numerous replicate buds were sampled from parent polyps.

The dispersal of asexual recruits through the population was quantified by counting samples from fused polyps or buds on the same parent only once. The minimum and maximum contribution of asexual recruitment then dropped to 8 and $11 \%$ respectively (Table 2 ). Within this sample of physically separate polyps are 6 cases of genet repeats, consisting of $2(n=4), 3(n=1)$ and $4(\mathrm{n}=1)$ clone mates. The range in the relative contribution of sexual and asexual reproduction to each of the locations decreased when replicate buds from a single parent were excluded from the sample (Table 2).

The contribution of asexual recruitment to adult size classes was investigated by only including polyps of the above reproductive size $(9 \mathrm{~cm}$ diameter) in the sample. No clone mates were found in adult size classes, indicating that most buds do not survive beyond the smallest size classes and do not contribute to the growth of the adult population (Table 2). When asexual buds on parents were excluded from the sample, only 2 cases of genet repeats remained, of which both were between free-living polyps of above and below adult size. The presence of adult and juvenile clone mates provides evidence that some asexual buds survive to maintain the genotype within the adult population.

\section{Genetic variation}

Genotypic frequencies for 20 of the 28 locus-location combinations differed significantly from Hardy-Weinberg expectations at the low-sediment site, due to large heterozygote deficiencies (Table 3). Deviations were not as great at the high-sediment site, with genotypic frequencies of less than half (12 of 28) of the loci-location combinations differing significantly from Hardy-Weinberg expectations. There was a predominance of heterozygote deficiencies at this site for each of the locus-location combinations (24 of 28), although their number and magnitude was not as great as at the low-sediment site (28 of 28; Table 3). Departures from Hardy-Weinberg equilibria were even greater when locations were pooled, and both sites displayed similar patterns of departure across loci.

Large positive $F_{\text {IS }}$ values were obtained for all variable loci in the pooled samples from each site, producing a mean $( \pm \mathrm{SE}) F_{\text {IS }}$ value of $0.571(0.018$; Table 4$)$. A test of the Wahlund effect was performed to investigate the importance of spatial subdivision in producing the observed heterozygote deficiencies, due to local larval dispersal or inbreeding. The sum of the variances of allelic frequencies among sites at each locus $\left(\sum \mathrm{s}_{p}^{2}\right)$, was compared to the proportional heterozygote deficiencies for that locus $\left(H_{\mathrm{e}}-H_{0}\right.$, where $H_{\mathrm{e}}$ is the proportion of heterozygotes expected within a panmictic population, and $H_{0}$ is the average proportion of heterozygotes observed within collections; $\mathrm{Li}$ 1976). The observed variation $( \pm \mathrm{SE})$ among collections $\left(\sum \mathrm{s}^{2}{ }_{p}=0.08 \pm 0.02\right)$ was sufficient to explain $25 \%$ of the average heterozygote deficit among the 7 loci $\left(H_{\mathrm{e}}-H_{\mathrm{o}}=0.323 \pm 0.057\right)$. Mean $( \pm \mathrm{SE})$ genetic variation between sites was significant $\left(F_{\mathrm{ST}}=0.030 \pm 0.002\right.$; $\left.\chi^{2}, \mathrm{p}<0.01\right)$. Hierarchical $F$-statistic analyses indicated that almost $80 \%$ of the variation occurred among locations within sites $\left(F_{\mathrm{ST}}=0.080\right)$, rather than among sites $\left(F_{\mathrm{ST}}=0.022 ;\right.$ Table 4$)$. 
Table 3. Fungia fungites. Departures from Hardy-Weinberg equilibria $\left(D_{\mathrm{s}}\right)$ at each of 4 locations within each site. Repeated genets are counted once (only applicable at high-sediment site). Significant departures (after Yates \& Bonferroni corrections) are indicated by ${ }^{*} \mathrm{p}<0.05,{ }^{* *} \mathrm{p}<0.01,{ }^{* * *} \mathrm{p}<0.001$

\begin{tabular}{|c|c|c|c|c|c|c|c|c|c|c|c|}
\hline \multirow[b]{2}{*}{ Locus $^{\mathrm{L}}$} & \multirow[b]{2}{*}{ cation $\rightarrow$} & \multicolumn{5}{|c|}{ Low-sediment site } & \multicolumn{5}{|c|}{ - High-sediment site } \\
\hline & & 1 & 2 & 3 & 4 & $\begin{array}{c}\text { All } \\
\text { locations }\end{array}$ & 1 & 2 & 3 & 4 & $\begin{array}{c}\text { All } \\
\text { locations }\end{array}$ \\
\hline $\operatorname{Pgm}^{*}$ & $D_{\mathrm{s}}$ & -0.231 & $-0.752^{* * *}$ & $-0.571^{* * *}$ & -0.353 & $-0.529^{* * *}$ & -0.378 & $-0.932^{* * *}$ & $-0.856^{* * *}$ & $-0.496^{* * *}$ & $-0.746^{* * *}$ \\
\hline Mdhp* & $D_{\mathrm{s}}$ & -0.409 & -0.310 & -0.124 & -0.271 & $-0.289^{* *}$ & 0.126 & -0.294 & $-0.711^{* *}$ & -0.196 & $-0.131^{* *}$ \\
\hline$I d h^{*}$ & $D_{\mathrm{s}}$ & $-0.577^{* * *}$ & $-0.790^{* * *}$ & $-0.631^{* * *}$ & $-0.929^{* * *}$ & $-0.821^{* * *}$ & -0.603 & $-0.930^{* * *}$ & $-1.000^{* * *}$ & -1.000 & $-0.943^{* * *}$ \\
\hline Pgi $^{*}$ & $D_{\mathrm{s}}$ & $-0.594^{* * *}$ & -0.159 & $-0.487^{* * *}$ & $-0.433^{*}$ & $-0.452^{* * *}$ & -0.207 & 0.062 & 0.046 & -0.230 & -0.077 \\
\hline$V l^{*}$ & $D_{\mathrm{s}}$ & $-0.556^{* * *}$ & $-0.544^{* * *}$ & $-0.941^{* * *}$ & $-0.790^{* * *}$ & $-0.714^{* * *}$ & -0.535 & $-0.688^{* * *}$ & -0.453 & 0.035 & $-0.451^{* * *}$ \\
\hline$P d g h^{*}$ & $D_{\mathrm{s}}$ & -0.621 & $-1.000^{* * *}$ & $-0.857^{* * *}$ & $-1.000^{* * *}$ & $-0.883^{* * *}$ & -1.000 & $-1.000^{* * *}$ & $-1.000^{* *}$ & -0.756 & $-0.923^{* * *}$ \\
\hline$G d h^{*}$ & $D_{\mathrm{s}}$ & $-0.594^{* * *}$ & $-0.757^{* * *}$ & $-0.587^{* * *}$ & $-0.952^{* * *}$ & $-0.737^{* * *}$ & $-1.000^{* * *}$ & $-0.578^{* * *}$ & $-1.000^{* * *}$ & -0.455 & $-0.723^{* * *}$ \\
\hline
\end{tabular}

Large heterozygote deficiencies and considerable genetic variation among locations characterise both study sites. To determine whether cryptic species were responsible, 2 different tests were performed. The first test investigated linkage disequilibria between pairs of loci. The presence of cryptic species would be expected to produce linkage disequilibria because the heterozygote deficiencies vary across several loci. At the low- and high-sediment sites respectively, only 1 and 3 of the possible 21 pair-wise associations between loci were significant, producing an average total $\mathrm{p}$-value of 0.206. Additionally, the presence of cryptic species would produce consistent patterns of linkage at both populations. However, significance levels for pairs of loci were very different at the high- and lowsediment populations. The second test investigated the potential for 3 or more cryptic species to be present within my sample. A dissimilarity matrix (City-block distance) between specimens was generated, based on

Table 4. Fungia fungites. Hierarchical analysis of standardised genetic variance within $\left(F_{\mathrm{IS}}\right)$ and between $\left(F_{\mathrm{ST}}\right)$ high- and low-sediment populations

\begin{tabular}{|lcc|}
\hline Locus & $F_{\text {IS }}$ & $F_{\text {ST }}$ \\
\hline$G d h^{*}$ & 0.622 & 0.054 \\
$I d h^{*}$ & 0.810 & 0.023 \\
$M d h p^{*}$ & 0.232 & 0.004 \\
$P d g h^{*}$ & 0.880 & 0.002 \\
$P g i^{*}$ & 0.275 & 0.020 \\
$P g m^{*}$ & 0.561 & 0.017 \\
$V I^{*}$ & 0.553 & 0.052 \\
& & \\
Mean $( \pm$ SE) & $0.517(0.018)$ & \\
& & \\
& & \\
Hierarchical F-statistics & Variance & \\
\hline Location within site & $0.030 .002)$ \\
Location within total & 0.406 & 0.080 \\
Site within total & 0.053 & 0.022 \\
\hline
\end{tabular}

the genotypic variation at each of the 7 loci analysed. The presence of cryptic species would be expected to produce obvious grouping within the sample. However, a frequency histogram of dissimilarity measures showed no patterns of grouping, having a normal distribution with matching mean, median, and modal categories $(\mathrm{N}=19498$, skewness $=-0.061$, kurtosis $=-0.140)$. Heterozygote deficiencies were consistent across most loci, and coupled with taxonomic investigation of specimens, I concluded that each population sample consisted of only 1 species, Fungia fungites.

\section{DISCUSSION}

\section{Asexual budding, chronic sedimentation and population maintenance}

Asexual budding in Fungia fungites made an undetectable contribution to adult population growth under conditions of chronic sedimentation. Although 10 to $30 \%$ of the population were derived asexually, these individuals existed mainly as buds attached to parents, or as free-living juveniles, and no adult clone mates were found (Table 2). There was evidence that some adults were derived asexually, in the form of fused polyps and adult polyps with juvenile clone mates. Genetic data indicate that polyp fusion only occurs between asexual buds, and 2 sets of fused polyps were above adult size. Also, polyps of the same genotype are assumed to be produced via asexual budding, and there were 5 adult polyps (1 fused set) that had the same genotype as at least 1 juvenile. Consequently, there are 6 known instances where adult polyps were asexually derived. The minimum contribution of asexual reproduction to adult size classes is therefore $18 \%$, despite the absence of clone mates. Among free-living polyps $(\mathrm{n}=59)$ however, there were only 3 genets with more than 1 clone mate, all of which consisted of 2 polyps. The lack of clone mates within such a small 
area indicate that asexual reproduction does not contribute to population growth, but may maintain some genotypes in the adult population. The genetic structure of this population therefore reflects its maintenance via sexual recruitment, from which all genotypes originated, and there is a limited contribution of asexual recruits to population demography above the initial stage of bud production.

Based on a high incidence of budding, I predicted that asexual reproduction would produce clone mates in all size classes at the sediment-affected site. Indeed, bud production is a proposed mechanism enabling recolonisation following disturbance events (Chadwick \& Loya 1990, Krupp et al. 1992, Kramarsky-Winter \& Loya 1996). However, successful re-colonisation requires suitable conditions and sufficient time between disturbances for buds to grow to adult size. Following acute disturbances, conditions may return to those suitable for population growth, as has been suggested for populations of fungiid corals following fresh-water runoff (Krupp et al. 1992, Jokiel et al. 1993, Goffredo \& Chadwick-Furman 2000). In contrast, mortality rates associated with chronic disturbances are likely to persist, fluctuating relative to disturbance duration and intensity. In this population, sedimentation represents a chronic stress that contributes to size-specific polyp mortality (Gilmour 2002). Buds emerging and detaching into conditions responsible for the death of their parent are highly susceptible, and therefore have little chance of survival. Asexual budding in Fungia fungites may be an effective mechanism for site re-colonisation following rare acute disturbances, but seems ineffectual under conditions of chronic sedimentation.

Sexual reproduction underlies adult demography at the sediment-affected site, despite the low proportion of sexual recruits (0.08) compared to asexual buds (0.43). Therefore, sexual recruits are likely to have higher survival rates than asexual buds. Unlike asexual buds, settling larvae display a degree of habitat selectivity, preferring crevices or ridges on vertical faces of substrata rather than exposed horizontal surfaces (Harrison \& Wallace 1990, author's pers. obs.). Larvae of a variety of fungiid species recruit to cryptic habitats such as caves (Goffredo \& Chadwick-Furman 2000), and because Fungia fungites larvae display similar settlement preferences, they are less likely to settle in areas prone to sediment accumulation. Additionally, sexual recruits detach from the substrata at a larger size (6.5 $\mathrm{cm}$ diameter) than asexual buds from parents (2.5 $\mathrm{cm}$ diameter), and I have found sexual recruits of up to $20 \mathrm{~cm}$ diameter still attached to the substrata. By remaining attached in areas of low sediment stress throughout their smallest size classes, when mortality rates are highest, sexual recruits may greatly increase their chance of survival to adult size classes.

\section{Patterns of sexual recruitment}

Inbreeding and local larval recruitment at both study sites was evident in large positive $F_{\text {IS }}$ values, major heterozygote deficiencies and small-scale genetic variation. Heterozygote deficiencies are common in marine invertebrate populations (Zouros \& Foltz 1984, Avise 1994, Carvalho 1994). The magnitude reported in this study is exceptional, but the deficiencies are consistent across most loci and are unlikely the result of analysis errors or the presence of cryptic species. Heterozygote deficiency and fine scale genetic variation may arise from self-fertilisation, asexual reproduction, inbreeding, and local larval recruitment (Zouros \& Foltz 1984, Avise 1994, Ayre et al. 1997). The predominance of heterozygote deficiencies have been reported for populations of sea anemones (Russo et al. 1994), gorgonians (Brazeau \& Harvell 1994) and stony corals (Ayre \& Dufty 1994, Ayre et al. 1997, Miller 1997, 1998, Ayre \& Hughes 2000). Explanations for these studies include: short dispersal of eggs and sperm, skewed sex ratios in dioecious species, selffertilisation in hermaphroditic species, philopatric larval dispersal, and local dispersal of asexual propagules. A combination of 2 or more of these traits is likely to result in a small effective population size and a high level of inbreeding.

The hard coral Fungia fungites is dioecious, and therefore self-fertilisation of gametes is not responsible for the observed heterozygote deficiencies. Asexual replication of genotypes deficient in heterozygotes is unlikely to be responsible, given its negligible contribution to the growth of either population. Inbreeding and local larval recruitment are the most likely explanation for my results, given the site locations and the biology of $F$. fungites, and have been inferred from other recent studies of coral populations (Ayre \& Dufty 1994, Brazeau \& Harvell 1994, Ayre et al. 1997, Miller 1997, 1998, Whittaker 1997, Hughes 1999, 2000, Ayre \& Hughes 2000). Sex ratios in fungiid populations are often skewed (Harrison \& Wallace 1990, KramarskyWinter \& Loya 1996), and the location of male and female polyps, coupled with the dispersal ability of sperm, will reduce the size of breeding groups (Johnson \& Black 1984, Brazeau \& Harvell 1994, Ayre \& Hughes 2000). Gamete dispersal during spawning periods may be restricted in the study populations, given their location within sheltered bays. Importantly, eggs produced by fungiid corals are small and negatively buoyant (Krupp 1983, Harrison \& Wallace 1990, author's pers. obs.), unlike the egg-sperm bundles of many spawning corals. When expelled from the polyp mouth, eggs sink onto or adjacent to the female (Krupp 1983, author's pers. obs.). Fertilisation and gametogenesis is therefore likely to occur close to the substrata, in 
the vicinity of parent polyps. Larval philopatry is frequently documented in viviparous anthozoans, but generally not associated with species whose gametes are fertilised externally (but see Ayre \& Hughes 2000). However, in F. fungites, larvae may also be highly restricted in their dispersal given that gametogenesis probably occurs in the near vicinity of parent polyps. The resultant larvae are more likely to explore microhabitats close to the substrata than to swim up into the water column, where mortality rates are high. In aquaria, fungiid larvae displayed limited active swimming, primarily exploring the substrata (Krupp 1983). The small size of breeding groups and the limited dispersal of gametes and larvae substantially increases the probability of inbreeding in these populations of $F$. fungites, potentially between siblings.

Most of the genetic variation in this study of Fungia fungites was between locations within sites, rather than between sites. It is common in studies of corals for the smallest scale of investigation to show the highest level of genetic variation (see Ayre \& Hughes 2000). This includes hermaphroditic species, which spawn positively buoyant gametes that develop into planktonic larvae. Therefore, larvae that routinely recruit to a population are produced locally, despite the potential for larvae to disperse over longer distances. Indeed, the longer a larva remains in the water column, and presumably the further it travels, the less likely it is to recruit successfully. Regular patterns of localised larval recruitment produce fine-scale genetic variation within reefs. However, the potential for long distance dispersal of larvae means they will periodically recruit from distant reefs. These rare and episodic recruitment events are likely to vary substantially over spatial and temporal scales. The historic consequences of recruitment of larvae from distant reefs will be to dramatically reduce genetic variation between the reefs on which cohorts become established. Small amounts of gene flow from a common source reduces genetic variation over large spatial scales, relative to the fine-scale variation that is detected within reefs (Ayre \& Hughes 2000).

\section{Population dynamics of Fungia fungites at the high-sediment site}

The importance of sexual and asexual recruitment to populations of clonal organisms is routinely inferred from the number and sizes of constituent genets, of which genotypic diversity is a measure. Disturbance events have a variable effect on genotypic diversity, with populations showing both increases (Ayre 1984, Hunter 1993) and decreases (Coffroth \& Lasker 1998) with moderate to high levels of disturbance. Theoreti- cal predictions suggest that genotypic diversity will be highest at intermediate levels of disturbance (Sebens \& Thorne 1985). Clearly, the number and size of genets will vary in relation to reproductive modes, levels of recruitment, habitat-specific survival of recruits, and the types and frequency of disturbance events (see Coffroth \& Lasker 1998).

Asexual budding in Fungia fungites results from polyp injury, and bud recruitment increases with moderate to high levels of sedimentation. Similarly, coral fragmentation occurs via colony damage during storms, and recruitment of fragments increases with moderate to high levels of disturbance. The survival of asexual propagules following their initial recruitment requires suitable local conditions for them to become established (e.g. Heyward \& Collins 1985, Hunter 1993, Brazeau \& Harvell 1994, Coffroth \& Lasker 1998, Smith \& Hughes 1999). If these requirements are not met, then there may be major disparities between the production and early recruitment of asexual propagules and their contribution to population maintenance. The population of $F$. fungites at the high-sediment site provides such an example, whereby a large number of asexual recruits have little influence on adult demography. This highlights the need to distinguish between levels of recruitment of asexual propagules to different life-history stages, examples being the initial stages of production, recruitment to the juvenile population, and recruitment to adult (sexually mature) size classes. This population also highlights the differences between acute disturbance events, which at a low frequency may allow the establishment of the asexual recruits they generate, and chronic disturbances, which are unlikely to allow the establishment of asexual recruits if the conditions result in adult mortality.

This study indicates that in recent history, sexual recruitment underlies population maintenance of Fungia fungites at the sediment-affected site, and that the contribution of asexual buds is limited. Without experimental evidence it is not possible to determine whether bud mortality is primarily related to chronic mean levels of sedimentation, or elevated levels of sedimentation resulting from the storms and cyclones which frequently occur in this region of Australia. If bud mortality is primarily related to periods of storm swell, then the contribution of buds to adult demography may be substantial over the years when storm activity has been less intense. Recruitment of sexual larvae to this population is routinely produced by the adult stock. There is little genetic evidence of recent recruitment from outside the population, and no recruitment to terracotta settlement plates $(10 \times 10 \times$ $2 \mathrm{~cm}, \mathrm{n}=120$ ) was observed following 3 mass spawning episodes. However, sexual recruitment to clonal populations is characteristically episodic, even in those 
displaying high levels of connectivity to outside populations (Ayre 1984, Stoddart 1984, Avise 1994, Ayre et al. 1997). Evidence from this study suggests that the long-term persistence of $F$. fungites at the sedimentaffected site may depend on periods of reduced adult mortality and increased survival of asexual recruits, and/or substantial pulses in larval recruitment from outside the population.

Acknowledgments. M. Johnson and D. Ayre have provided valuable assistance while also commenting on the manuscript. R. Black, L. Beesley, T. Finston, A Baird, M. Stuckey and J. Stoddart also have contributed greatly to this work. This research was funded by Sigma Xai, grants in-aid-of research, and the University of Western Australia. I am indebted to the Australian Institute of Marine Science (W.A. operations) and Hamersley Iron, Pty Limited, who have provided ongoing equipment and infrastructure support.

\section{LITERATURE CITED}

Avise JC (1994) Molecular markers, natural history and evolution. Chapman \& Hall, New York

Ayre DJ (1984) The effect of sexual and asexual reproduction on geographic variation in the sea anemone Actinia tenebrosa. Oecologia 62:222-229

Ayre DJ, Dufty S (1994) Evidence for restricted gene flow in the viviparous coral Seriatopora hystrix on Australia's Great Barrier Reef. Evolution 48:1183-1201

Ayre DJ, Hughes TP (2000) Genotypic diversity and gene flow in brooding and spawning corals along the Great Barrier Reef, Australia. Evolution 54:1590-1605

Ayre DJ, Hughes TP, Standish RJ (1997) Genetic differentiation, reproductive mode and gene flow in the brooding coral Pocillopora damicornis along the Great Barrier Reef, Australia. Mar Ecol Prog Ser 159:175-187

Bell G (1982) The masterpiece of nature: the evolution and genetics of sexuality. Croom Helm, London

Boschma H (1923) Experimental budding in Fungia fungites. Proc K Ned Akad Wet 26:88-96

Bradshaw AD (1965) Evolutionary significance of phenotypic plasticity in plants. Adv Genet 13:115-156

Brazeau DA, Harvell CD (1994) Genetic structure of local populations and divergence between growth form in a clonal invertebrate, the Caribbean octocoral Briareum asbestinum. Mar Biol 119:53-60

Carvalho GR (1994) Genetics of aquatic clonal organisms. In: Beaumont AR (ed) Genetics and evolution of aquatic organisms. Chapman \& Hall, London, p 291-322

Chadwick NE, Loya Y (1990) Regeneration after experimental breakage in the solitary reef coral Fungia granulosa Klunzinger, 1879. J Exp Mar Biol Ecol 142:221-234

Coffroth MA, Lasker HR (1998) Population structure of a clonal gorgonian coral: The interplay between clonal reproduction and disturbance. Evolution 52:379-393

Gilmour JP (2002) Acute sediment deposition causes sizespecific mortality and asexual budding in the mushroom coral Fungia fungites. Mar Freshw Res 53(4)

Goffredo S, Chadwick-Furman NE (2000) Abundance and distribution of mushroom corals (Scleractinia: Fungiidae) on a coral reef at Eilat, northern Red Sea. Bull Mar Sci 66: 241-245

Harrison PL, Wallace CC (1990) Reproduction, dispersal, and recruitment of scleratinian corals. In: Dubinsky Z (ed) Ecosystems of the world: coral reefs. Elsevier Publishers, New York, p 133-207

Heyward AJ, Collins JD (1985) Fragmentation in Montipora ramosa: the genet and ramet concept applied to a reef coral. Coral Reefs 4:35-40

Hughes RN (1989) A functional biology of clonal animals. Chapman \& Hall, London

Hughes TP, Baird AH, Dinsdale EA, Moltschaniwskyj NA, Pratchett MS, Tanner JE, Willis BL (1999) Patterns of recruitment and abundance of corals along the Great Barrier Reef. Nature 397:59-63

Hughes TP, Baird AH, Dinsdale EA, Moltschaniwskyj NA, Pratchett MS, Tanner JE, Willis BL (2000) Supply-side ecology works both ways: the link between benthic adults, fecundity, and larval recruits. Ecology 81:2241-2249

Hunter CL (1993) Genotypic variation and clonal structure in coral populations with different disturbance histories. Evolution 47:1213-1228

Jackson JBC, Coates AG (1986) Life cycles and evolution of clonal (modular) animals. Phil Trans R Soc Lond B 313:7-22

Johnson MS, Black R (1984) The Wahlund effect and the geographical scale of variation in the intertidal limpet Siphonaria sp. Mar Biol 79:295-302

Johnson MS, Threlfall TJ (1987) Fissiparity and population genetics of Coscinisterias calamaria. Mar Biol 93:517-525

Jokiel PL, Hunter CL, Taguchi S, Waterai L (1993) Ecological impact of a fresh water 'reef kill' in Kaneohe Bay, Oahu, Hawaii. Coral Reefs 12:177-184

Kramarsky-Winter E, Loya Y (1996) Regeneration versus budding in fungiid corals: a trade-off. Mar Ecol Prog Ser 134:179-185

Krupp DA (1983) Sexual reproduction and early development of the solitary coral Fungia scutaria (Anthozoa: Scleractinia). Coral Reefs 2:159-164

Krupp DA, Jokiel PL, Chartrand TS (1992) Asexual reproduction by the solitary scleractinian coral Fungia scutaria on dead parent coralla in Kanehoe Bay, Oahu, Hawaiian Islands. Proc 7th Int Symp Coral Reefs 1:527-534

Li CC (1976) First course in population genetics. Boxwood Press, Pacific Grove, CA

Miller K (1997) Genetic structure of black coral populations in New Zealand's fjords. Mar Ecol Prog Ser 161:123-132

Miller K (1998) Short-distance dispersal of black coral larvae: inference from spatial analysis of colony genotypes. Mar Ecol Prog Ser 163:225-233

Pearson EO, Hartley HO (1956) Biometrika tables for statisticians, Vol 1. Cambridge University Press, Cambridge

Reynolds J, Weir BS, Cockerham CC (1983) Estimation of coancestry coefficient: basis for short-term genetic distance. Genetics 105:767-779

Rice WR (1989) Analysing tables of statistical tests. Evolution 43:223-225

Richardson BJ, Baverstock PR, Adams M (1986) Allozyme electrophoresis. A handbook for animal systematics and population studies. Academic Press, London

Russo CAM, Solé-Cava AM, Thorpe JP (1994) Population structure and genetic variation in two tropical sea anemones (Cnidaria, Actinia) with different reproductive strategies. Mar Biol 119:267-276

Sebens KB, Thorne BL (1985) The coexistence of clones, clonal diversity, and the effects of disturbance. In: Jackson JBC, Buss LW, Cook RE (eds) Population biology and evolution of clonal organisms. Yale University Press, New Haven, CT, p 357-398

Selander RK (1970) Behaviour and genetic variation in natural populations. Am Zool 10:53-66 
Selander RK, Smith MH, Yang SH, Johnson WE, Gentry JB (1971) Biochemical polymorphism and systematics in the genus Peromyscus. I. Variation in the old-field mouse. (Peromyscus polionotus). Stud Genet 6:49-90

Smith LD, Hughes TP (1999) An experimental assessment of survival, re-attachment and fecundity of coral fragments. J Exp Mar Biol Ecol 235:147-164

Stearns SC (ed) (1992) Trade-offs. In: The evolution of life histories. Oxford University Press, Oxford, p 72-90

Stoddart JA (1984) Genetic structure within populations of the coral Pocillopora damicornis. Mar Biol 81:19-30

Swofford DL, Selander RB (1981) BIOSYS-1. A FORTRAN program for the comprehensive analysis of electrophoretic data in population genetics and systematics. J Hered 72:281-283

Warner RR (1975) Sexual-asexual evolutionary equilibrium? Am Nat 112:960-962

Editorial responsibility: George Humphrey (Contributing Editor), Sydney, Australia
Weir BS, Cockerham CC (1984) Estimating F-statistics for the analysis of population structure. Evolution 38:1358-1370

Whittaker K (1997) Dispersal and recolonization potential of five species of hermatypic corals (scleractinia) at Ningaloo Reef, Western Australia. Unpublished PhD Thesis, University of Western Australia

Williams GC (1975) Sex and evolution. Princeton University Press

Williams GC, Mitton JB (1973) Why reproduce sexually? J Theor Biol 39:545-554

Wright S (1978) Evolution and the genetics of populations, Vol 4. Variability within and among natural populations. University of Chicago Press

Zouros E, Foltz DW (1984) Possible explanations for heterozygote deficiency in bivalve molluscs. Malacologia 25: 583-591

Submitted: November 20, 2000; Accepted: January 24, 2002 Proofs received from author(s): May 14, 2002 